\title{
Research on Crack Propagation Simulation of Mental Construction of Bridge Crane Based on Damage Mechanics
}

\author{
Xiaogang $\mathrm{Qu}^{1,2}$, Gening $\mathrm{Xu}^{2}$ and Xiaoning $\mathrm{Fan}^{2}$ \\ ${ }^{1}$ School of Mechanical \& Electronical Engineering, Lanzhou University of \\ Technology, Lanzhou 730050, China \\ ${ }^{2}$ College of Mechanical Engineering, Taiyuan University of Science and \\ Technology, Taiyuan 030024, China \\ atitanic198036@126.com, ${ }^{b} x u g$ ening@sina.com, ${ }^{c}$ fannyfxn@163.com
}

\begin{abstract}
Based on continuum damage mechanics theory, fatigue crack propagation of girder of founding crane was researched under cyclic stress. According to the damage fatigue experimental data of Q345, undetermined parameter of damage model was got, and fatigue damage model of girder of founding crane was deduced under cyclic stress. Based on this research, with the method of live-dead element of finite element analysis, expansion process in the crack producing stage of founding crane was simulated, and crack propagation process in the different temperature was compared, what's more, the influence of temperature to the crack propagation has been analyzed.
\end{abstract}

Keywords: Damage Mechanics, Damage evolution model, Finite element, Casting crane, Crack propagation

\section{Introduction}

It is a common way to analyze the crack propagation with the fracture mechanics theory in the crack research. The crack and its expansion law have been researched widely in the classical fracture mechanics [1-5]. In the methods of fracture mechanics research, firstly suppose the conditions of crack exist, to seek the length of crack, inherent resistance of the crack growth that the materials resist, and ration relation among stress of structural failure caused by crack expanding in high speed. Therefore, the defects of objects in the classical fracture mechanics just show the existence of bizarre defects, and mental construction of crane has been working many years before appearance of cracks. Calculating with the fracture mechanics method is the telophase life-span of mental construction of crane, so the evaluation of prophase life-span of mental construction of crane (stage of crack producing) has defects with the fracture mechanics methods. However, the researching contents of the damage mechanics are continuous distribution defects and various defects of dislocation, micro-cracks and micro-holes in the objects, which are called damage. In the macroscopic views, they spread all over the whole object. The happening and development of these defects manifest the distortion and breakage of materials. With the various loading conditions, the damage mechanics researches destructive process and laws caused by the development of damaging distortion of objects.

\section{Fatigue Damage Theory}

According to damage mechanical theory [6], damage variable $D$ stands for the expansion of micro-void. And Micro cracks lead the material into the damage real effective bearing area $\tilde{A}$ which is denotes as decrease degree. That's to say, formation 
and extending of micro-cracks and micro-gaps result in cross-sectional area $A$ of test specimens reduce to practical effective loaded area $\tilde{A}$; Meanwhile, the diminution of effective loaded area results in the increase of practical stress, which leads to degradation of mechanical property of materials. According to the definition of damage mechanics assume:

$$
1-D=\tilde{A} / A
$$

The cross section effective bearing area reduced, lead to the increase of effective stress, effective stress can be expressed as:

$$
\tilde{\sigma}=\sigma /(1-D)
$$

The fatigue damage is caused by the material with lower ultimate strength under the alternating load. Some local area or wide area first yield, plastic deformation of high degree is found in a local region, it is a kind of the fracture process of its trans-granular fracture.

Based on continual damage mechanics theory, fatigue damage is expressed by dissipation potential function. This text use X. H. Yang, N. LI, et al., proposed dissipation potential model [7], to express the degree of damage accumulation:

$$
\phi=\frac{Y^{2}}{2 S_{0}} \frac{\dot{r}}{(1-D)^{a_{0}}}
$$

Where:

$S_{0} \longrightarrow$ materials relates to the temperature constant;

$a_{0} \longrightarrow$ material constant;

$\dot{r} \longrightarrow$ each cycle of accumulated plastic strain;

According to the literature [8], the extent of damage accumulation is described by function $\beta(\sigma, T)$ instead of $a_{0}$; experimental cyclic load is pulsation cycle, $\sigma$ is expressed by the biggest stress ' $\sigma_{\text {max }}$ ', Expression (4) is

$$
\phi=\frac{Y^{2}}{2 S_{0}} \frac{\dot{r}}{(1-D)^{1-k\left(\sigma_{\max }, T\right)}}
$$

Literature [9] explained the theory of fatigue damage in detail. Assuming that plasticity deformation leads to interior damage and energy consumption, so dissipation potential function is

$$
\phi=\phi_{P}\left(\sigma, \sigma_{Y}, R, D\right)+\phi_{D}\left(Y, r, T, \varepsilon_{e}, D\right)
$$

Where:

$\sigma-$ stress tensor;

$\sigma_{Y} \longrightarrow$ Material the initial yield stress;

$R$ - Isotropic cumulative plastic strain hardening parameters;

$Y \longrightarrow$ strain energy release rate;

$r \_$accumulated plastic strain;

$T-$ absolute temperature;

$\varepsilon_{e}$ elastic strain tensor;

$\phi_{P}$ elastic strain tensor, in view of the loss of plastic parts;

$\phi_{D} \longrightarrow$ dissipation part of the damage.

In view of the damage dissipation part $\phi_{D}$, damage kinetics law can be expressed as: 


$$
\dot{D}=-\frac{\partial \phi_{D}}{\partial Y} \dot{\lambda}=-\frac{\partial \phi}{\partial Y}
$$

Substituting equation (4) into (6), we obtain

$$
\dot{D}=\left(-\frac{Y}{S_{0}}\right) \frac{\Delta \dot{r}}{(1-D)^{1-k\left(\sigma_{\max }, T\right)}}
$$

The strain energy release rate is

$$
Y=-\frac{\sigma_{e q}^{2}}{2 E(1-D)^{2}} R_{V}
$$

Here

$$
\Delta \tilde{\sigma}_{e q}=\frac{\sigma_{e q}}{1-D} .
$$

Based on strain equivalence principle [10], the stress-strain relations is

$$
\Delta \tilde{\sigma}_{e q}=K \Delta r^{\mathrm{m}}
$$

$K, \mathrm{~m} \longrightarrow$ constant

Substituting (8) and (9) into (7), Equation (10) can be obtained:

$$
\dot{D}=\left(-\frac{K^{2} R_{V}}{2 E S_{0}}\right) \frac{\Delta r^{2 m}}{[(1-D)]^{1-\mathrm{k}\left(\sigma_{\max }, T\right)}} \Delta \dot{r}
$$

Integrating equation (10), and $D=N / N_{f}$, the boundary conditions $\left.D\right|_{N=N_{0}}=D_{0},\left.D\right|_{N=N_{f}}=1$ are generated,

$$
D=1-\left(1-D_{0}\right)\left[\left(1-N / N_{f}\right)\right]^{k\left(\sigma_{\max }, T\right)}
$$

Equation (11) is deduced based on damage mechanics theory of fatigue damage evolution model.

\section{The Application of Damage Mechanics Theory in the Finite Element Analysis}

First of all, define the Fatigue damage evolving model formula (11), introduce the damage evolving equation into the constitutive relation, equilibrium equation, geometrical relationship, initial condition and boundary condition. At the moment, damage field, stress field, strain field act on the unit together. But if the coupling of damage field and stress field, strain field is considered in the all units, and the cycle life is very long, the calculating work will consume much time. Now with the method of effective stress in the damage mechanics, the procedure is:

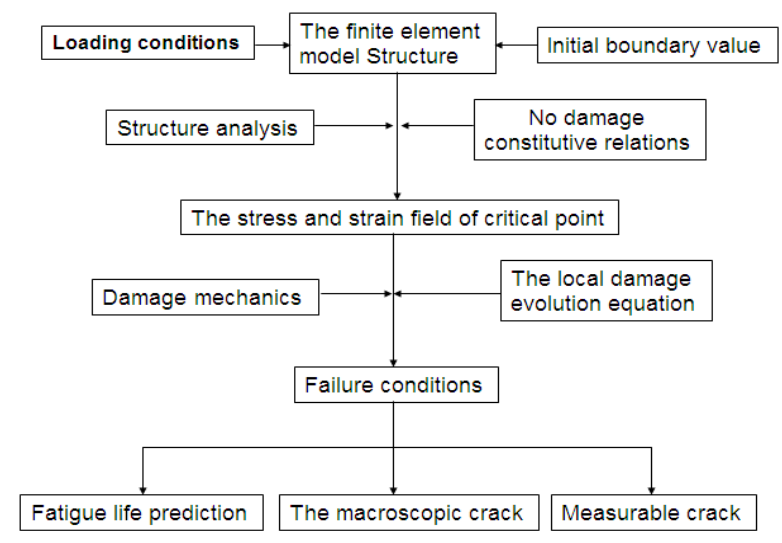

Figure 1. Schematic Diagram of Structure Damage Analysis 
Test parameters based on one-dimensional stretching which are got in the fatigue experiment, according to the three-dimensional stress model of damage equivalent stress put forward by Lemaitre [11].

$$
\sigma_{\text {deq }}=\bar{\sigma} \sqrt{\frac{2}{3}(1+\mu)+(1-2 \mu)\left(\frac{\sigma_{H}}{\bar{\sigma}}\right)^{2}}
$$

$\bar{\sigma}-$ Von Mises equivalent stress

$\sigma_{H} \longrightarrow$ hydrostatic pressure

$\mu$ Poisson ratio

Stretch and compress have different influence to the damage evolution, because of crack closing effect. According to the different state of stretch and compress, amendatory damage equivalent stress is different.

Stretch

$$
\sigma_{d e q}^{*}=\sigma_{d e q}
$$

Compress

$$
\sigma_{d e q}^{*}=-\left(\frac{1-D}{1-h D}\right)^{1 / 2} \sigma_{d e q}
$$

To the complicated components, the damage caused by different stresses is different, because the stress of every component is different. The finite element method should be used to calculate damage field, which is to calculate the damage of every unit. Using damage process of unit simulates destructive process of components. Unit damage will be got by accumulating every cyclic damage increment. After one circulation, the damage increment of unit is the superimposing of fatigue damage increment and creep damage increment. From the damage evolution formula, damage increment of the unit $N$ circulation is related to the damage caused by unit $N-1$ circulation (expressed by $D_{N-1}$ ), $D_{N-1}$ takes the place of $D$, damage increment $\Delta D_{N}$ caused by the unit $\mathrm{N}$ circulation is solved by numerical integration, therefore, after $\mathrm{N}$ circulations, the accumulating damage of unit is $D_{N}=D_{N-1}+\Delta D_{N}$, when $N=0$, the initial damage of unit is $D_{0}$, its value is determined by initial situations of components.

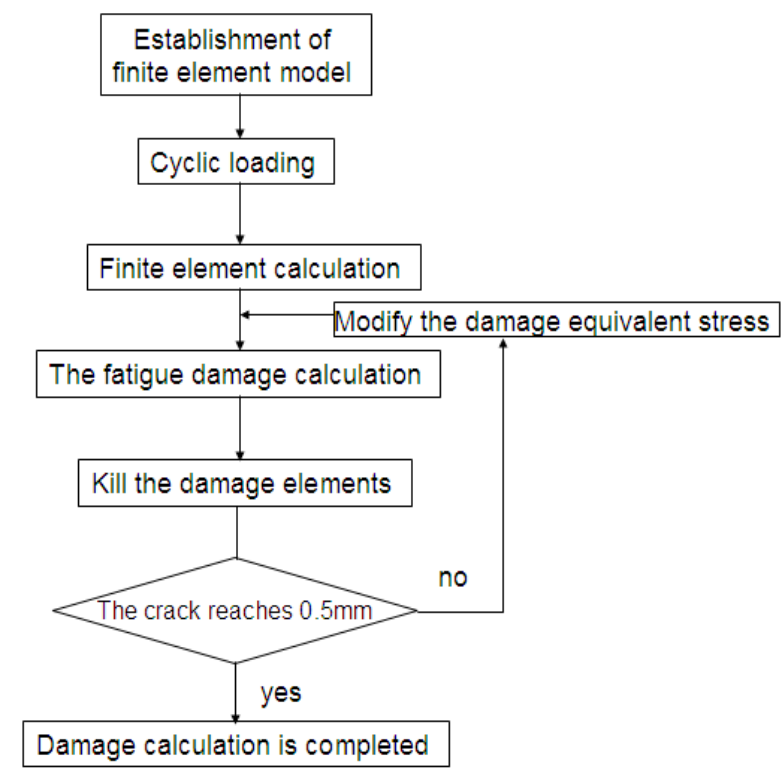

Figure 2. Flow Chart of Structure Damage Program Design 


\section{Experiment Result Analysis}

The test material is Q345 which is commonly used in crane, test conditions for stress control, pulsation cycle, Sine wave load. Before the test, keep samples in the furnace for 30 minute. The environment is atmospheric for laboratory. The load frequency $\mathrm{f}=0.3 \mathrm{~Hz}$ when have stretch meter, the load frequency $\mathrm{f}=4 \mathrm{~Hz}$ when haven't stretch meter. At the same temperature $420^{\circ} \mathrm{C}$ under different stress level and the same stress level (0 $480 \mathrm{MPa}$ ) Cycling test under different temperature between $15^{\circ} \mathrm{C}$ and $420^{\circ} \mathrm{C}$.

4.1. The Analysis of the Experimental Data under the Same Stress Level (0 480mpa) and the Different Temperature

Table 1. Same Stress Level (0-480 MPa) Data at Different Temperatures

\begin{tabular}{|l|l|l|l|l|}
\hline \multicolumn{1}{|l|}{} & $D_{0}$ & $\mathrm{k}$ & \multicolumn{1}{|c|}{$N_{f} /$ cycle } & $T /{ }^{\circ} \mathrm{C}$ \\
\hline 1 & 0 & 0.03993 & 2571 & 15 \\
\hline 2 & 0.0206 & 0.04994 & 3024 & 100 \\
\hline 3 & 0.0108 & 0.07548 & 24792 & 200 \\
\hline 4 & 0.0174 & 0.12222 & 61192 & 250 \\
\hline 5 & 0.0198 & 0.01528 & 287366 & 300 \\
\hline 6 & 0.0115 & 0.04036 & 84104 & 375 \\
\hline 7 & 0.0168 & 0.03173 & 38875 & 400 \\
\hline 8 & 0.0104 & 0.02779 & 8341 & 420 \\
\hline
\end{tabular}

By the data can be seen in table 1 , the Stress cycle life maximizing at $300^{\circ} \mathrm{C}$, Now in 300 , With two curve fitting in $15-420^{\circ} \mathrm{C}$.

\subsubsection{Damage Model in $15-300^{\circ} \mathrm{C}$}

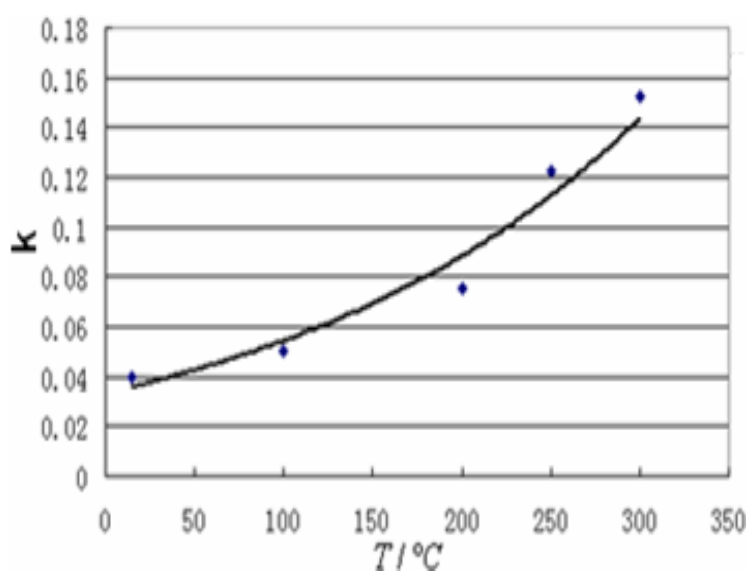

Figure 3. T and $\mathbf{k}$ Curve Fitting at $15-300^{\circ} \mathrm{C}$

$k=0.0335 e^{0.0048 T}$

$\mathrm{R} 2=0.959$

$$
D=1-\left(1-D_{0}\right)\left(1-N / N_{f}\right)^{0.0335 e^{0.0048 T}}
$$


4.1.2. Damage Model in $300-420^{\circ} \mathrm{C}$

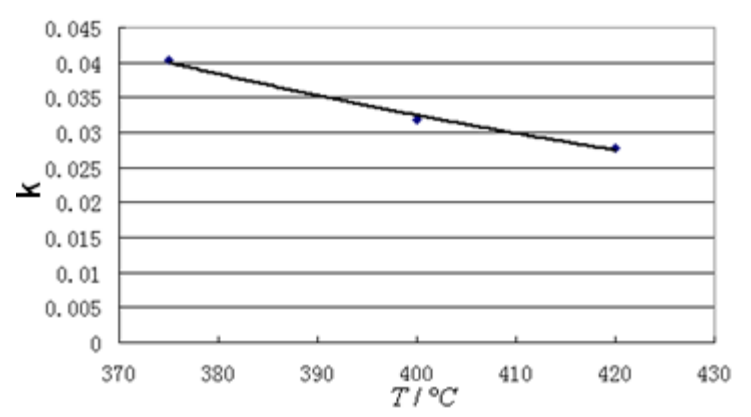

Figure 4. T and k Curve Fitting at $300-420^{\circ} \mathrm{C}$

$k=0.9143 e^{-0.0083 T}$

$D=1-\left(1-D_{0}\right)\left(1-N / N_{f}\right)^{0.9143 e^{-0.0083 T}}$

$\mathrm{R} 2=0.9897$

4.2. The Test Data of the Same Temperature $420^{\circ} \mathrm{C}$ under Different Stress Level

Table 2. Different Stress Levels of Test Data at $420^{\circ} \mathrm{C}$

\begin{tabular}{|l|l|l|l|l|}
\hline $\begin{array}{l}\text { parameter } \\
\text { test specinimen }\end{array}$ & $D_{0}$ & \multicolumn{1}{|c|}{$\mathrm{k}$} & $N_{f} /$ cycle & $\sigma_{\max } /$ Mpa \\
\hline 1 & 0.0134 & 0.04525 & 320614 & $0 \sim 420$ \\
\hline 2 & 0.0036 & 0.04438 & 238362 & $0 \sim 430$ \\
\hline 3 & 0.0262 & 0.04136 & 144743 & $0 \sim 440$ \\
\hline 4 & 0.0142 & 0.03963 & 91863 & $0 \sim 460$ \\
\hline 5 & 0.0307 & 0.0328 & 27302 & $0 \sim 470$ \\
\hline 6 & 0.0104 & 0.02779 & 8341 & $0 \sim 480$ \\
\hline 7 & 0 & 0.02319 & 2188 & $0 \sim 490$ \\
\hline
\end{tabular}

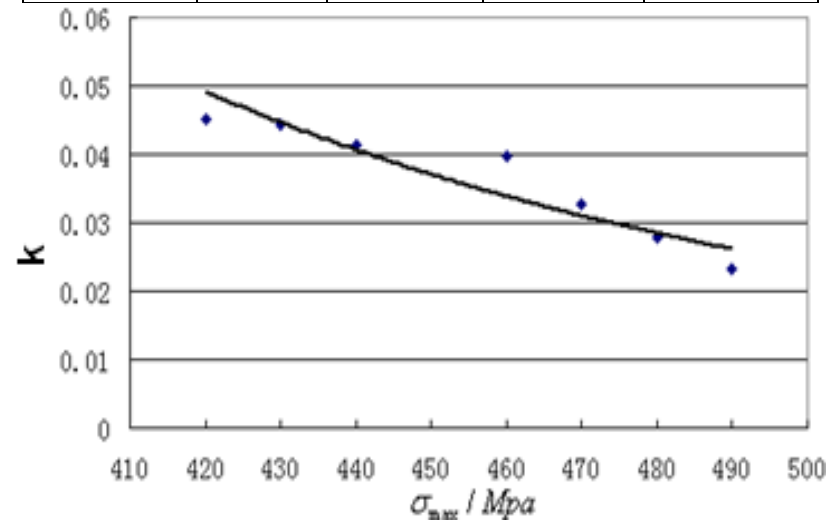

Figure 5. $\sigma_{\max }$ and k Curve Fitting at $300-420^{\circ} \mathrm{C}$

$k=2.2514 e^{-0.0091 \sigma_{\text {max }}}$

$\mathrm{R} 2=0.8845$

$$
D=1-\left(1-D_{0}\right)\left(1-N / N_{f}\right)^{2.2514 e^{-0.0091^{\sigma_{\max }}}}
$$




\subsection{MnR Mechanics Performance Test Data at Different Temperatures:}

Table 3. Different Temperature and Yield Strength/Ultimate Strength Test Data

\begin{tabular}{|l|l|l|l|}
\hline temperature $/{ }^{\circ} \mathrm{C}$ & $\sigma_{S} / M P \mathrm{a}$ & $\sigma_{\mathrm{b}} / M P \mathrm{a}$ & $\varphi / \%$ \\
\hline 20 & 378 & 582 & 58 \\
\hline 100 & 312 & 516 & 63 \\
\hline 200 & 319 & 528 & 56 \\
\hline 300 & 283 & 576 & 52 \\
\hline 400 & 233 & 527 & 63 \\
\hline 420 & 238 & 517 & 70.5 \\
\hline
\end{tabular}

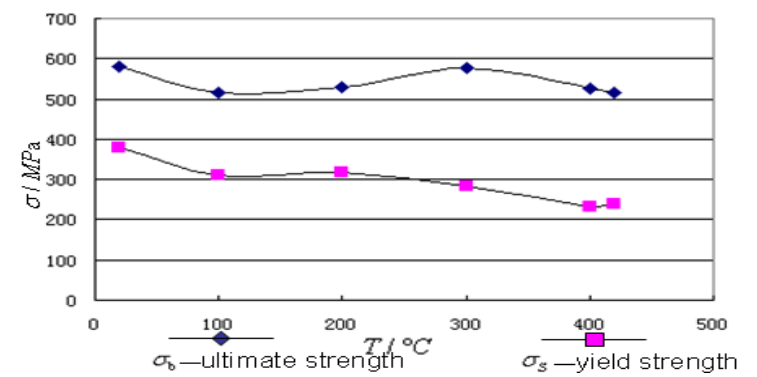

Figure 6. Different Temperature and Yield Strength/Ultimate Strength Curve Fitting

The ultimate strength and temperature fitting function relation:

$\sigma_{\mathrm{b}}=4.072192199248056 \times 10^{-10} T^{5}-4.412721256265577 \times 10^{-7} T^{4}+1.544129660087676 \times 10^{-4} T^{3}-0.01717947799185 T^{2}$

$$
-0.17836192042617 T+5.912730263157935 \times 10^{2}
$$

$$
\mathrm{R} 2=0.9671
$$

Suppose the influence of $\sigma_{\max } 、 T$ to function $k\left(\sigma_{\max }, T\right)$ isn't linking .In order to do math processing conveniently, following form of linear superposition is assumed further.

$$
k\left(\sigma_{\max }, \mathrm{T}\right)=k\left(\sigma_{\max }\right)+k(T)
$$

\subsection{1. $15-300^{\circ} \mathrm{C}$ Damage Model}

$$
D=1-\left(1-D_{0}\right)\left(1-N / N_{f}\right)^{2.2514 e^{-0.0091^{\sigma_{\max }}}+0.0335 e^{0.0048 T}}
$$

\subsection{2. $300-420^{\circ} \mathrm{C}$ Damage Model}

$$
D=1-\left(1-D_{0}\right)\left(1-N / N_{f}\right)^{2.2514 e^{-0.0091^{\sigma_{\max }}}+0.9143 e^{-0.0083 T}}
$$

\section{Example Analysis}

Take the 180T founding crane as an example, the dangerous point in the joint of girder and middle section of crane is being analyzed. In Figure 7, the dangerous point 1 is limit inferior location of crane web that corresponds to bonding point of Major separator. The damage field and stress field, strain field are linked only in the dangerous point of crane girder. 


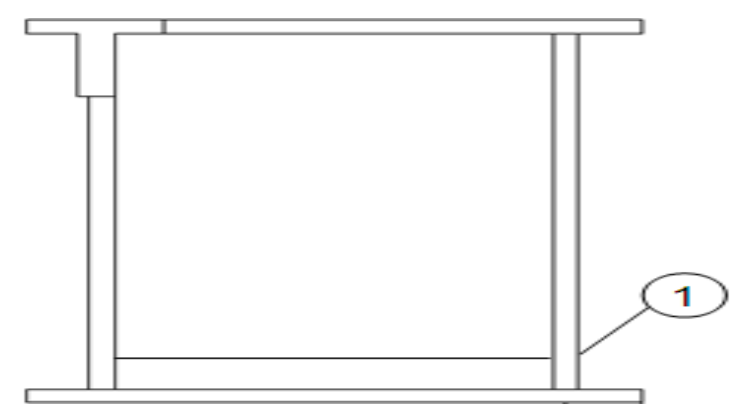

Figure 7. Sectional View of Crane Girder

\subsection{The Crack Propagation Process of Dangerous Point lin the Different Temperature}

Figure 8 and Figure 9 are the crack propagation process in the different temperature respectively, Y-axis is the crack propagation dimension $L_{\mathrm{c}}$, unit is $\mathrm{mm}, \mathrm{X}$-axis is cycle index of loading.

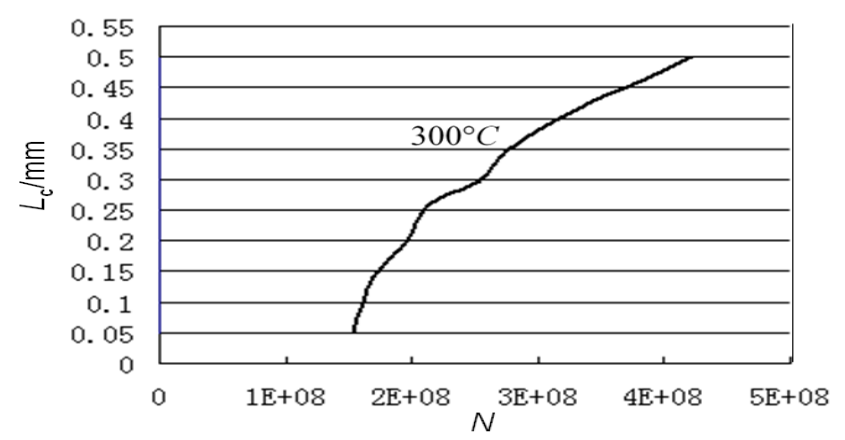

Figure 8. The Crack Propagation Process at $300^{\circ} \mathrm{C}$

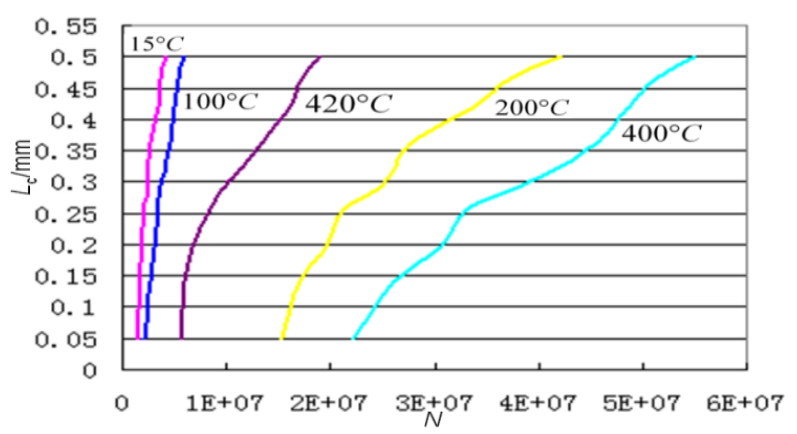

Figure 9. The Crack Propagation Process at the Temperature $15^{\circ} \mathrm{C} 、 100^{\circ} \mathrm{C}, 200^{\circ} \mathrm{C}, 400^{\circ} \mathrm{C}$ and $420^{\circ} \mathrm{C}$

\subsection{The Crack Propagation Simulating Process in the Finite Element Model at} $200^{\circ} \mathrm{C}$

Temperature is an important factor that affects the strength of materials. $300^{\circ} \mathrm{C}$ is the more remarkable of the strength of dynamic strain aging (DSA), DSA curbed the development of cyclic creep and cyclic softening effectively, meanwhile the cycle life is greatly improved, at the moment it reaches a peak.

When the temperature deviates from the DSA temperature range, serious cyclic creep and cyclic softening emerged. Cyclic creep and fatigue interact which leads to the reduction of life expectancy. 


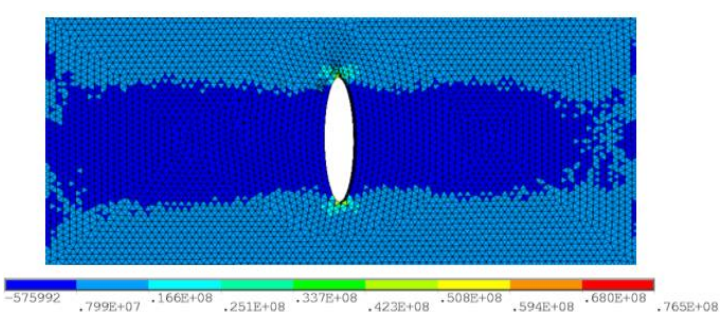

Figure 10. The Crack Propagation at $\mathrm{N}=1.6532 \mathrm{E}+07$

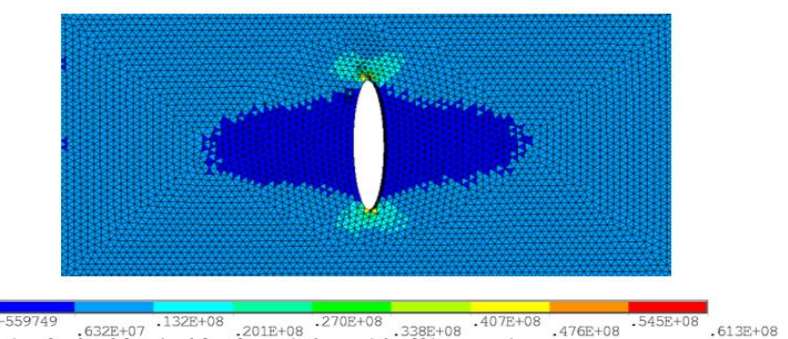

Figure 11. The Crack Propagation at $\mathrm{N}=2.2586 \mathrm{E}+07$

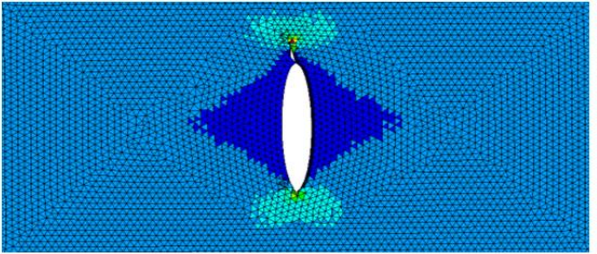

Figure 12. The Crack Propagation at $\mathrm{N}=2.9673 \mathrm{E}+07$

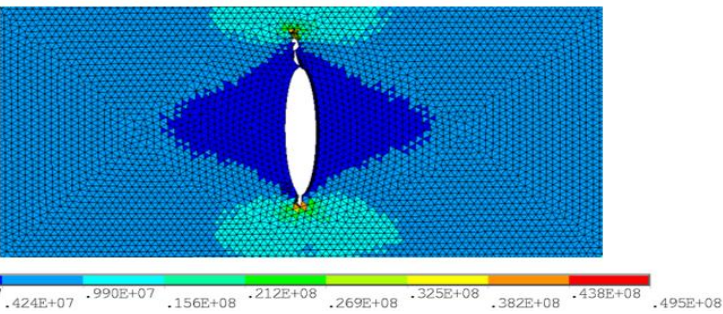

Figure 13. The Crack Propagation at $\mathrm{N}=3.2389 \mathrm{E}+07$

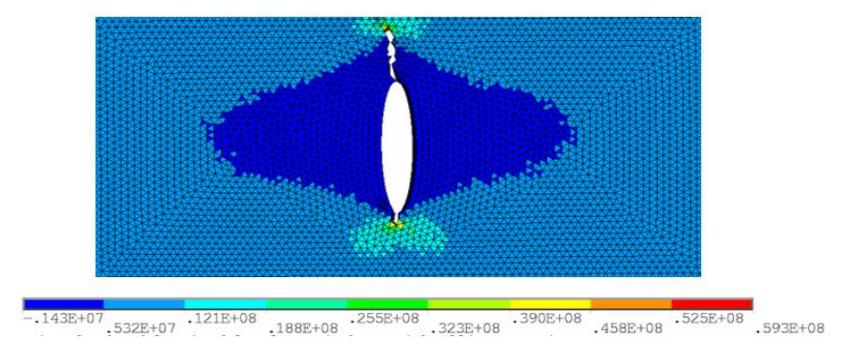

Figure 14. The Crack Propagation at $\mathrm{N}=3.9667 \mathrm{E}+07$

As can be seen from the results of finite element analysis, with the increase of load frequency, crack along the direction of extension of partition, due to the stress singularity at the crack tip region, stresses in the crack tip stress value is significantly higher than that in other area value, the area of the unit first killed, the formation of crack extension direction. 


\section{Conclusion}

In the life evaluation of crane, the crack initiation stage accounted for about $80 \%$ of all life, the life assessment of the crack initiation stage is extremely important. On the basis of damage mechanics theory, the paper simulates the propagation of crane during the crack initiation stage, this method has clear physical meaning and good theoretical basis, and it has a very strong guidance for engineering application.

6.1 The life-span in the crack initiation stage has been simulated in the finite element model, when the crack expands to $0.5 \mathrm{~mm}$ (measured crack dimension), this crack dimension is regarded as upper limit dimension in the crack producing stage, at the moment, the life-span is prophase life-span.

6.2 Link the temperature field, stress field, strain field and the damage field. Describe the damage situation of mental construction of crane under cyclic loading.

6.3 Simulate the crack propagation laws of crane in different temperature with fatigue experimental data in different temperature.

\section{Acknowledgements}

This paper is supported by the National Natural Science Foundation of China (51275329), the National Science-technology Support Projects for the 12th five-year plan No.2011BAK06B05, and Youth Fund Program of Taiyuan University of Science and Technology (20113014).

\section{References}

[1] A. A. Griffith, "The Phenomena of Rupture and Flow in Solids", Philosophical Transactions of the Royal Society of London, Sereis A, vol. 221, (1921), pp. 163-199.

[2] G. R. Irwin, "Analysis of Stresses and Strains near the End of a Crack Transfering of a Plate”, Journal of Applied Mechanics, vol. 24, no. 4, (1957), pp. 361-364.

[3] P. C. Paris M P G and W. P. Anderson, "A Rational Analytic Theory of Fatigue", The Trend in Engineering, vol. 13, (1961), pp. 9-14.

[4] R. G. Forman, "Study of Fatigue Crack Initiation from Flaws Using Fracture Mechanics Theory", Engineering Fracture Mechanics, vol. 4, no. 2, (1972), pp. 333-345.

[5] P. Paris and F. Erdogan, "A Critical Analysis of Crack Propagation Laws", Journal of Basic Engineering, vol. 85, no. 4, (1963), pp. 528-533.

[6] Y. Shouwen and F. Xiqiao, "Damage mechanics", Tsinghua University Press, 12 Version, vol. 1, (1997), pp. 48-54

[7] X. H. Yang, N. Li, Z. H. Jin and T. J. Wang, "A continuous low cycle fatigue damage model and its application in engineering materials", Int. J. Fatigue, vol. 19, (1997).

[8] C. Ling and J. Jialing, "Low cycle fatigue damage model and its experimental verification", Jinshu Xuebao/Acta Metallurgica Sinica, vol. 41, no. 2, (2005) February, pp. 157-160.

[9] D. Krajcinovic and J. Lemaitre, "Continuum Damage Mechanics: Theory and Application", Springer Verlag Berlin, (1987).

[10] D. Krajcinovic and J. Lemaitre, "Continuum damage mechanics", Theory and Application, Springer Verlag Berlin, (1987), pp. 37-89.

[11] J. Lemaitre, “A Course on Damage Mechanics”, Berlin: Springer-Verlag, (1992).

\section{Author}

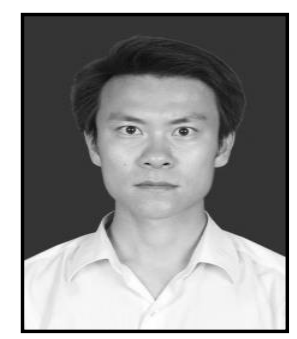

Xiaogang QU, Address correspondence to this author at the College of Mechanical Engineering, Taiyuan University of Science and Technology,030024, P.R. China; Tel: +8613403692910; e-mail:titanic198036@126.com 